\section{Earth's water may have been inherited from material similar to enstatite chondrite meteorites}

LAURETTE PIANI ${ }^{1}$, YVES MARROCCHI ${ }^{2}$, THOMAS

RIGAUDIER $^{1}$, DORIAN THOMASSIN ${ }^{1}$, MR. LIONEL G. VACHER, PHD ${ }^{3}$ AND BERNARD MARTY ${ }^{4}$

${ }^{1} \mathrm{CRPG}, \mathrm{CNRS}$-Lorraine Université

${ }^{2} \mathrm{CRPG}, \mathrm{CNRS}-$ Université Lorraine

${ }^{3}$ Washington University in St. Louis

${ }^{4}$ CRPG Université de Lorraine

Presenting Author: laurette.piani@univ-lorraine.fr

Earth is the only planet of our solar system with liquid water on its surface. This is a fundamental characteristic, as water played a major role both in geological processes and for the development of life. It is commonly considered that water was delivered to Earth by hydrated bodies such as hydrated asteroids formed in the outer Solar System (e.g., 1-2). Nonetheless, the water content of the main Earth's building blocks is still poorly known. Yet, potential analogues of these building blocks are available on Earth: the meteorites from the enstatite chondrite (EC) group that have similar isotopic composition to terrestrial rocks (3-4).

In this study, we have determined the bulk hydrogen concentration and isotopic composition of a series of ECs having different degrees of metamorphism (types 3 to 6) using an elemental analyzer coupled to an isotope ratio mass spectrometer (EA-IRMS) with a method minimizing the atmospheric water contamination (5-6). We found that ECs have bulk hydrogen contents (reported as water equivalents) ranging from 0.08 to $0.54 \mathrm{wt} \% \mathrm{H}_{2} \mathrm{O}$ and that the water content is higher in the least metamorphosed chondrites. Using the secondary ion mass spectrometer (SIMS) IMS 1280 HR2 at CRPG, we identified high water concentrations (between 0.27 and 1.23 wt.\%) with an average $\mathrm{dD}_{\mathrm{SMOW}}$ value of $-147 \pm 16 \%$ in the chondrule mesostasis of the pristine EC Sahara 97096 (6).

Taken together, these results indicate that EC-like material could have provided at least 3 times the mass of the water of the Earth's oceans to the forming Earth. EC hydrogen and nitrogen isotopic compositions match those of Earth's mantle (Fig. 1); so EC-like asteroids might have contributed these volatile elements to Earth's crust and mantle (6).

(1) A. Morbidelli et al., Meteoritics 35, 1309-1320 (2000)

(2) B. Marty, Earth Planet. Sci. Lett. 313-314, 56-66 (2012)

(3) M. Javoy et al., Earth Planet. Sci. Lett. 293, 259-268 (2010)

(4) N. Dauphas, Nature 541, 521-524 (2017)

(5) L. G. Vacher et al., Geochim. Cosmochim. Acta 281, 5366 (2020)

(6) L. Piani et al., Science 369, 1110-1113 (2020)

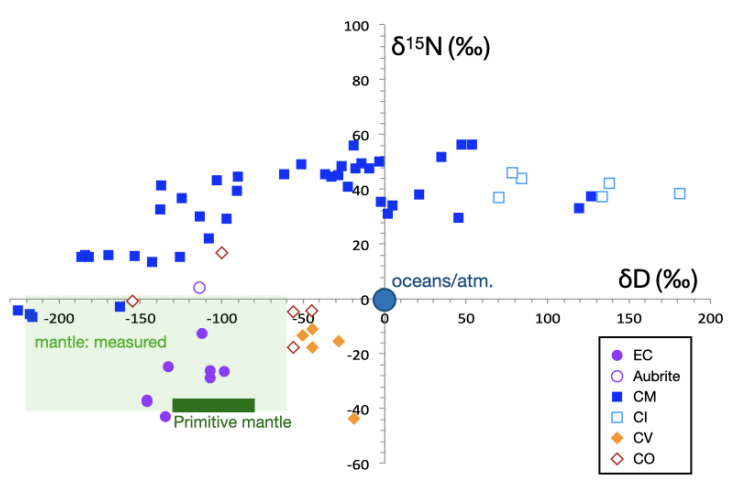

